\title{
PENGARUH COUNTRY OF ORIGINDAN PERCEIVED QUALITY TERHADAP MINAT BELI SEPEDA MOTOR HONDA BEAT DI KOTA SUMBAWA
}

\author{
The Influence Of Contry Of Origin and Perceived Quality on The Interest in \\ Buying a Honda Beat Motorcycle in The City Of Sumbawa \\ 1Dara Karismawati, ${ }^{2} \mathrm{Abdul}$ Salam, ${ }^{3} \mathrm{Fendy}$ Maradita \\ Manajemen, Fakultas Ekonomi dan Bisnis, Universitas Teknologi Sumbawa \\ Jl. Raya Olat Maras, Batu Alang, Moyo Hulu, NTB. \\ Email : darakarisma99@gmail.com
}

\begin{abstract}
Abstrak
Penelitian ini bertujuan untuk mengetahui : 1) Pengaruh Country of origin terhadap Minat beli sepeda motor Honda Beat di Kota Sumbawa . 2) Pengaruh Perceived quality terhadap Minat beli sepeda motor Honda Beat di Kota Sumbawa. Model yang digunakan dalam analisis data adalah uji instrumen penelitian, uji asumsi klasik, analisis regresi berganda, dan uji hipotesis.Alat analisis yang digunakan dalam penelitian ini adalah SPSS 16.Data yang digunakan yaitu data primer dan data sekunder dengan pengambilan sampel secara purposive sampling. Hasil penelitian menunjukkan bahwa 1) Country of originberpengaruh positif dan signifikan yang ditunjukkan dengan nilai thitung sebesar 3,140 lebih besar dari tabel sebesar 1,996dan signifikansi sebesar 0,003 lebih besar dari 0,05. 2) Perceived qualityberpengaruh positif dan tidak signifikan yang ditunjukkan dengan nilai thitung sebesar 0,566 lebih kecil dari tabel sebesar 1,996 dan signifikansi sebesar 0,573 lebih besar dari 0,05. 3) Country of origin dan Perceived quality berpengaruh signifikan secara bersama-sama yang ditunjukakan dengan nilai fnitung 6,842 lebih besar dari ftabe/ sebesar 3,13.
\end{abstract}

Kata Kunci: Country of origin, Perceived quality, Minat beli.

\begin{abstract}
The research aims to find out: 1) The Country of Origin influence on the interest in buying Honda Beat motorcycles in Sumbawa town. 2) Effect of Perceived quality on the interest of buying Honda Beat motorcycles in Sumbawa town. The models used in data analysis are research instrument tests, classical assumption tests, multiple regression analyses, and hypothesis tests. The analysis tool used in this study is SPSS 16. Data used is primary data and secondary data with purposive sampling. The results showed that 1) the Country of Origineffect was positively and significantly indicated with a value of Thitung of
\end{abstract}


3.140 greater than the this of 1, 996and the significance of 0.003 is greater than 0.05 .2$)$ Perceived the positive and insignificant effect is shown with the value of Thitung of 0.566 smaller than the this of 1.996 and the significance of 0.573 is greater than 0.05 . 3) The Country of origin and Perceived quality of the significant effect jointly presented with the value of Fcount 6.842 greater than ftable of 3.13.

Keywords : Country of origin, Perceived quality, buying interest.

\section{PENDAHULUAN}

Salah satu sepeda motor yang ada di Indonesia adalah Honda. Honda merupakan jaringan pemasaran di Indonesia yang telah menguasai pangsa pasar yang ada di Indoesia, sepeda motor Honda merupakan produksi asal Jepang yang memiliki keunggulan teknologi yang telah diakui oleh seluruh dunia dan telah terbukti dalam berbagai kesempatan. Adapun sepeda motor Honda yang paling banyak diburu oleh para konsumen yaitu sepeda motor Honda Beat. Saat ini Honda Beat menjadi sepeda motor matic yang paling banyak diminati oleh para konsumen. Menurut penelitian yang di lakuka oleh Yanthi \& Jatra (2015) mengenai, “ Pengaruh Country of Origin,Brand Image, dan Perceived Quality terhadap Minat Beli Sepeda Motor Honda Beat di Kota Sumbawa " mengatakan bahwa country of origin berpengaruh positif dan signifikan terhadap minat beli sepeda motor Honda Beat di kota Denpasar.

Persepsi kualitas (perceived quality) dapat didefiniskan sebagai bentuk persepsi konsumen terhadap keseluruhan kualitas atau keunggulan produk atau jasa terhadap alternatif- alternatif yang ada sesuai dengan tujuan yang diinginkan, presepsi kualitas mencerminkan perasaan konsumen secara menyeluruh mengenai suatu produk (Keller, 2013). Secara kasat mata tingkat penggunaan sepeda motor di kota Sumbawa sangat tinggi, dan menurut data Badan Pusat Statistik (BPS) pengguna sepeda motor di sumbawa mencapai 435.102.177 dan bahkan hampir setiap rumah pasti memiliki motor bahkan lebih dari satu sehingga membuat peneliti ingin mengetahui apa saja faktor yang mempengaruhi minat beli dengan judul penelitian " Pengaruh County of Origin dan Perceived Quality terhadap Minat Beli sepeda Motor Honda di Kota Sumbawa".

\section{METODOLOGI}

a. Rancangan Penelitian

Penelitian ini menggunakan metode kuantitatif dengan pendekatan asosiatif.Metode kuantitatif merupakan penelitian dengan memperoleh data yang berbentuk angka atau data kualitatif yang diangkakan.Sedangkan pendekatan asosiatif merupakan pendekatan yang dilakukan untuk mengetahui pengaruh yang ditimbulkan ataupun juga hubungan yang dihasilkan 
antara dua variabel atau lebih.Data yang digunakan penelitian ini juga harus bersifat valid, realiabel dan obyektif yang berarti data yang digunakan harus sesungguhnya terjadi pada objek dengan data yang dilaporkan peneliti kemudian data yang digunakan harus konsisten antara data hari ini kemarin atau besok harus selalu sama.

b. Populasi

Menurut Sugiyono (2019) Populasi adalah wilayah generalisasi yang terdiri atas objek/subjek yang mempuyai kualitas dan karakteristik tertentu yang ditetapkan oleh peneliti untuk dipelajari dan kemudian ditarik kesimpulan.Populasiyang digunakan dalam penelitian ini adalah konsumen sepeda motor Honda Beat di Kota Sumbawa.

$$
\text { c. Sampel }
$$

Menurut Sugiyono (2019), sampel adalah sebagian dari jumlah dan karakteristik yang dimiliki oleh populasi tersebut. Jenis sampel dalam penelitian ini adalah sampel non probabilitas dimana anggota populasi tidak diberikan kesempatan yang sama untuk dijadikan anggota sampel. Tekhnik pengambilan sampel menggunakan metodepurposive sampling yaitu cara pengambilan sampel yang didasarkan pada pertimbangan-pertimbangan tertentu yang dianggap sesuai dan terkait dengan penelitian yang dilakukan. Alasan peneliti memilih sampel menggunakan purposive sampling adalah karena tidak semua populasi memiliki kriteria yang sesuai dengan yang peneliti tentukan. Oleh karena itukriteria-kriteria dalam menentukan sampel dalam penelitian ini adalah :

1. Konsumen yang menggunakan Sepeda Motor Honda Beat di Kota Sumbawa

2. Konsumen dengan rentang usia 17-40 Tahun

3. Menggunakan sepeda motor Honda Beat minimal 1 tahun

4. Berdasarkan jenis kelamin Karena populasi dalam jumlah yang sangat besar dan tidak diketahui maka dalam penelitian ini penentuan sampel menggunakan rumus Margin Of Eror (MOE),yaitu :

$$
n=\frac{Z}{}
$$

Keterangan :

$$
\begin{array}{llr}
\mathrm{n} & \multicolumn{1}{c}{\text { = Jumlah sampel }} \\
\mathrm{z} & =\text { Tingkat } & \text { keyakinan } \\
& \multicolumn{2}{l}{\text { yang dibutuhkan dalam }} \\
& \text { penentuan } & \text { sampel } \\
& 90 \%=1,64 & \\
\text { Moe } & =\text { Margin of } & \text { error yaitu } \\
& \text { tingkat } \quad \text { kesalahan } \\
& \text { maksimum } & \text { yang dapat } \\
& \text { ditoleransi } & \text { sebesar } \\
& 10 \% . &
\end{array}
$$




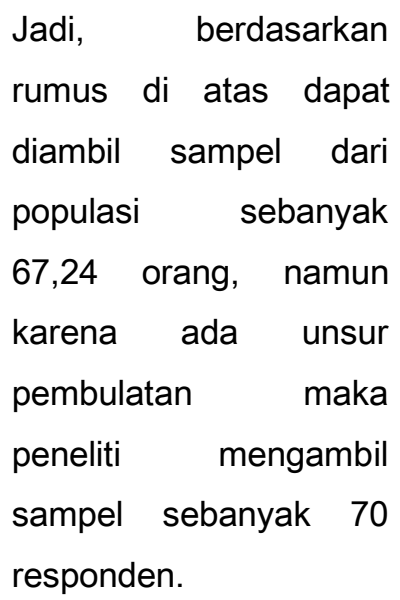

\section{d. Pengumpulan Data}

Data yang digunakan dalam penelitian ini menggunakan data primer dan data sekuder.

e. Uji Instrumen Penelitian

Menurut Sugiyono, (2014) analisis data merupakan kegiatan setelah data dari seluruh responden terkumpul. Kegiatan dalam analisis data adalah mengelompokkan data berdasarkan variabel dari seluruh responden, menyajikandata dari setiap variabel yang diteliti, melakukan perhitungan untuk menjawab rumusan masalah dan melakukan perhitungan untuk menguji hipotesis yang telah diajukan.

\section{f. Uji Asumsi Klasik}

Uji asumsi klasik bertujuan untuk mengetahui kondisi data yang dipergunakan dalam penelitian. Hal tersebut dilakukan agar diperoleh model analisis yang tepat Ghozali (2011). Model analisis regresi penelitian ini mensyaratkan uji asumsi terhadap data yang meliputi :

g. Uji Normalitas
Menurut Ghozali 2011), uji normalitas bertujuan untuk menguji apakah dalam model regresi variabel dependen dan variabel independen berdistribusi normal atau tidak. Model regresi yang baik adalah data normal atau mendekati normal. Uji normalitas yang digunakan dalam penelitian ini adalah kolmogorov smirnov, jika kolmogrov smirnov $>0,05$ maka data tersebut berdistribusi normal, sebaliknya jika nilai signifikan Kolmogorov Smirnov $<0,05$ maka data tersebut tidak berdistribusi normal.

$$
\text { h. Uji Heteroskedasitas }
$$

Uji Heterokedatisitas digunakan untuk menguji apakah dalam model regresi terjadi ketidaksamaan variabel dari residual satu pengamatan kepengamatan yang lain berbeda, maka disebut heteroskedastitas. Untuk mendeteksi ada atau tidaknya heteroskedastitas dapat dilakukan dengan uji Glejeser. Hasil uji dapat dilihat pada bagian koefisien antara variabel independen dengan absolute residual (Ghozali, 2011). Jika nilai signifikansi antara variabel independen dengan absolute residual lebih besar dari 0,05 maka tidak terjadi heteroskedastistas. Dan sebaliknya jika nilai signifikansi lebih kecil dari 0,05 maka terjadi heteroskedastistas.

i. Uji Multikolinearitas

Menurut Ghozali (2011), uji multikolinearitas bertujuan untuk menguji apakah sebuah model regresi 
ditemukan adanya korelasi antar variabel independen. Model regresi yang baik seharusnya tidak terjadi korelasi diantara variabel independen. Untuk mendeteksi ada atau tidaknya multikolinearitas dapat dilihat dari Tolerance dan Variance Inflantion Factor (VIF). Apabila nilai Tolerance $>0,10$ danVIF < 10, maka tidak terjadi multikolinearitas. Dan sebaliknya apabila nilai tolerance $<$ 0,10 dan VIF $>10$, maka terjadi multikoliniearitas (Ghozali, 2011).

\section{j. Analisis Linear Berganda}

Regresi berganda pada dasarnya merupakan perluasan dari regresi linier sederhana yaitu menambah jumlah variabel bebas yang sebelumnya hanya satu menjadi dua atau lebih variabel bebas (Sanusi, 2012). Regresi linier berganda pada penelitian ini digunakan untuk menguji pengaruh country of origin (X1) dan perceived quality (X2) terhadap minat beli $(\mathrm{Y})$.

\section{k. Uji Hipotesis}

Uji stastik t pada dasarnya menunjukkan seberapa jauh pengaruh satu variabel penjelas atau independen secara individual dalam menerapakn variabel dependen (Ghozali 2011). Ketentuan untuk mengetahui penerimaan atau penolakkan hipotesis ada dua cara yang dapat di pilih, yaitu:

1) Membandingkan nilai thitung dan tabel

Apabila nila thitung $<t_{\text {tabel }}$ maka Ha ditolak.Artinya tidak terdapat pengarug signifikan dari variabel indevenden secara individual terhadap variabel dependen.Sedangkan apabila thitung $>t_{\text {tabel }}$ maka $\mathrm{Ha}$ diterima. Artinya terdapat pengaruh signifikan dari variabel independen secara individual terhadap variabel dependen.

2) Melihat probabilitas value

Apabila probabilities value > derajat keyakinan $(0,05)$ maka Ha ditolak. Artinya tidak terdapat pengaruh signifikan dari variabel independen secara individual terhadap variabel dependen. Sedangkan apabila probabilities value < derajat keyakinan $(0,05)$ maka $\mathrm{Ha}$ diterima. Artinya terdapat pengaruh signifikan dari variabel independen secara individual terhadap variabel dependen.

Uji kelayakan model dalam penelitian ini menggunakan uji F. Menurut Ghozali (2011) uji statistik F pada dasarnya digunakan untuk menunjukan apakah semua variabel independen yang dimasukkan dalam model mempunyai pengaruh secara bersama-sama terhadap variabeldependen. Uji $F$ ini dilakukan dengan menggunakan tingkat kepercayaan 95\% $(a=0,05)$. Ketentuan untuk mengetahui hipotesis diterima 
atau ditolak ada 2 cara yang dapat dipilih, yaitu:

1) Membandingkan $\quad F_{\text {hitung }}$ dengan $F_{\text {tabel }}$

Apabila $F_{\text {hitung }}<\mathrm{F}_{\text {tabel }}$ maka $\mathrm{Ha}$ ditolak.Artinya variabel independen secara bersama-sama tidak mempengaruhi variabel dependen secara signifikan.Sedangkan apabila $F_{\text {hitung }}>F_{\text {tabel }}$ maka $\mathrm{Ha}$ diterima. Artinya variabel independen secara bersamasama mempengaruhi variabel dependen secara signifikan.

2) Melihat probabilities value

$$
\text { Apabila probabilities }
$$

value> derajat keyakinan $(0,05)$ maka Ha ditolak. Artinya variabel independen secara bersama-sama tidak mempengaruh variabel dependen secara signifikan. Sedangkan apabila probabilities value < derajat keyakinan $(0,05)$ maka $\mathrm{Ha}$ diterima. Artinya variabel independen secara bersamasama mempengaruhi variabel dependen secara signifikan.

\section{HASIL DAN PEMBAHASAN}

3.1. Deskripsi Data dan Responden
Data dalam penelitian ini didapatkan dengan cara menyebarkan kuisioner kepada responden. Jumlah kuisioner yang disebarkan adalah sebanyak 70 kuesioner. Responden dalam penelitian ini adalah konsumen yang menggunakan sepeda motor Honda Beat di Kota Sumbawa. Kriteria responden pada penelitian ini yaitu konsumen yang menggunakan sepeda motor Honda Beat di Kota Sumbawa dengan rentang usia 17-40 tahun.

Kuesioner yang disebarkan terdiri dari 12 pernyataan dengan rincian country of origin empat butir pernyataan, perceived quality empat butir pernyataan, dan minat beli terdiri dari empat pernyataan. Karakteristik responden diambil berdasarkan usia konsumen yang menggunakan sepeda motor Honda Beat di Kota Sumbawa.

3.1. Karakteristik Responden Berdasarkan Usia

Tabel 3.1. Responden Berdasarkan

Usia
\begin{tabular}{|l|l|l|}
\hline $\begin{array}{l}\text { Usia } \\
\text { Konsumen }\end{array}$ & $\begin{array}{l}\text { Jumlah } \\
\text { Konsumen }\end{array}$ & Persentase \\
\hline $17-25$ thn & 25 & $36 \%$ \\
\hline $25-33$ thn & 25 & $36 \%$ \\
\hline $33-40$ thn & 20 & $28 \%$ \\
\hline Total & 70 & $100 \%$ \\
\hline
\end{tabular}

Sumber: Data primer diolah peneliti, 2019

Berdasarkan Tabel 3.1 dapat dilihat bahwa jumlah responden berdasarkan usia 17-25 tahun sebanyak 25 orang konsumen sepeda motor 
Honda Beat dengan persentase $36 \%$, responden yang berusia 25-33 tahun sebanyak 25 orang konsumen sepeda motor Honda Beat dengan persentase $36 \%$, responden yang berusia $33-40$ tahun sebanyak 20 orang konsumen sepeda motor Honda Beat dengan persentase 28\%. Hal tersebut menunjukkan bahwakonsumen yang menggunakan sepeda motor Honda Beat adalah dominan berusia 17-40 tahun. Karena dapat dilihat dari tabel tersebut rata-rata yang menggunakan sepeda motor Honda Beat adalah konsumen dengan rentang usia dari 1740 tahun. Jadi dapat disimpulkan bahwa responden yang meggunakan Honda Beat adalah generasi milineal yang dimana responden tersebut rata-rata berumur dari 17-40 tahun. Generasi milineal sendiri adalah generasi yang lahir pada saat perkembangan teknologi telah hadir sehingaa membuat generasi ini mahir dalam teknologi, generasi ini melihat sebuah produk dari kualitas yang dimiliki tetapi dengan harga yang terjangkau.

\subsubsection{Karakteristik berdasarkan jenis} kelamin

Tabel 3.2 Responden berdasarkan jenis kelamin

\begin{tabular}{|l|l|l|l|}
\hline No & $\begin{array}{l}\text { Jenis } \\
\text { Kelamin }\end{array}$ & Jumlah & Persentase \\
\hline 1 & Laki-Laki & 24 & $35 \%$ \\
\hline 2 & Perempuan & 46 & $65 \%$ \\
\hline \multicolumn{2}{|l|}{ Total } & 70 & $100 \%$ \\
\hline
\end{tabular}

Sumber:Data diolah peneliti,2019
Berdasarkan data 4.2 diatas menunjukkan bahwa responden berjenis kelamin laki-laki dalam penelitian ini berjumlah 24dengan persentase $30 \%$ dan responden berjenis kelamin perempuan berjumlah 46dengan persentase $70 \%$. Hal ini menunjukkan bahwa sebagian besar jumlah responden berjenis kelamin perempuan. Honda Beat sendiri dikembangkan dengan konsep ukurannya yang ramping sehingga mudah dikendalikan saat digunakan dan memberikan stylingyang melebihi harapan para konsumen sehingga Honda Beat sendiri sangat cocok bagi pria maupun wanita yang menggunakan.

\subsection{Uji Analisis Data}

\subsubsection{Uji Asumsi Klasik}

Uji asumsi klasik dilakukan untuk mengetahui apakah hasil estimasi regresi yang dilakukan benar-benar layak digunakan atau tidak.Data yang diperoleh dari hasilkuesioner, selanjutnya akan diuji dengan uji asumsi klasik sebagai berikut :

1) Uji Normalitas

Uji normalitas bertujuan untuk menguji salah satu asumsi dasar analisis regresi berganda, dalam model regresi variabel dependen dan variabel independen berdistribusi normal atau tidak. 
Tabel 3.3. Hasil Uji Normalitas

One-Sample Kolmogorov-Smirnov Test

One-Sample Kolmogorov-Smirnov Test

\begin{tabular}{l|l|}
\hline & $\begin{array}{l}\text { Unstandardized } \\
\text { Residual }\end{array}$ \\
\hline Kolmogorov-Smirnov Z & .682 \\
Asymp. Sig. (2-tailed) & .741 \\
\hline $\begin{array}{l}\text { a. Test distribution is } \\
\text { Normal. }\end{array}$ & \\
\hline
\end{tabular}

Sumber: Data primer yang diolah, 2019

Berdasarkan hasil uji normalitas di atas, diperoleh Kolmogrov-Smirnov $Z$ sebesar0,682 $>5 \%$ dan Asymp. Sig (2-Tailed) sebesar 0,682 yang berarti lebih besar dari 0,05 , maka dapat disimpulkan bahwa data tersebut berdistribusi normal.

2) Uji Heteroskedastisitas

Uji heteroskedastisitas digunakan untuk menguji apakah dalam model regresi terjadi ketidaksamaan varian dari residual satu pengamatan kepengamatan yang lain. Untuk mendeteksi ada atau tidaknya masalah heteroskedastisitas digunakan uji Glejser dengan bantuan program SPSS 16 for windows. Hasil uji dapat dilihat pada bagian koefisien antara variabel independen dengan absolute residualapabila hasil regresi dari masing-masing variabel menunjukan nilai signifikansi lebih besar dari 0,05, maka dalam model regresi tidak terjadi heteroskedastisitas. Sebaliknya apabila nilai signifikansi lebih kecil dari 0,05 , maka dalam model regresi terjadi heteroskedastisitas. Hasiluji heteroskedastisitas disajikan pada tabel 3.4. berikut :

Tabel 3.4. Hasil Uji Heteroskedastisitas

\begin{tabular}{|l|l|l|l|}
\hline Variabel & Kriteria & Sig & Keterangan \\
\hline $\begin{array}{l}\text { Country of } \\
\text { Origin }\end{array}$ & 0,05 & 0,254 & $\begin{array}{l}\text { Tidak terjadi } \\
\text { heteroskeda } \\
\text { stisitas }\end{array}$ \\
\hline $\begin{array}{l}\text { Perceived } \\
\text { Quality }\end{array}$ & 0,05 & 0,544 & $\begin{array}{l}\text { Tidak terjadi } \\
\text { heteroskeda } \\
\text { stisitas }\end{array}$ \\
\hline
\end{tabular}

Sumber: Data primer yang diolah, 2019

Berdasarkan tabel 4.3 di atas, dapat disimpulkan bahwa tidak terjadi heteroskedastisitas pada semua variabel independen karena nilai signifikan variabel country of origin sebesar $0,254>0,05$ dan variabel perceived quality sebesar 0,544 >0,05.

3) Uji Multikolinearitas

Uji multikolinearitas bertujuan untuk mengetahui apakah dalam model regresi terdapat gejala korelasi antar variabel independen. Untuk mendeteksi ada atau tidaknya gejala multikolinearitas dapat dilihat pada nilai tolerance dan VIF yang dihitung menggunakan bantuan program SPSS 16 for windows. Jika nilai tolerance> 0,10 dan VIF $<10$, maka tidak terjadi multikolinearitas. Dan sebaliknya jika nilai tolerance $<0,10$ dan VIF $>10$, maka terjadi multikolinearitas. Hasil uji multikolinearitas disajikan pada tabel 3.5 berikut.

\subsubsection{Analisis Regresi Linier Berganda}

Alat analisis yang digunakan dalam penelitian ini adalah analisis regresi linier berganda. Analisis regresi linier berganda digunakan untuk mengetahui 
pengaruh country of origin $\left(\mathrm{X}_{1}\right)$ dan perceived quality $\left(\mathrm{X}_{2}\right)$ secara parsial terhadap minat beli $(\mathrm{Y})$. Analisis regresi linier berganda tersebut menggunakan program SPSS 16 for windows. Berdasarkan pengujian diperoleh hasil yang dapat disajikan dalam tabel 4.9 berikut:

Sumber :Data primer diolah peneliti, 2019 Berdasarkan hasil tersebut dapat diperoleh persamaan regresi berganda sebagai berikut:

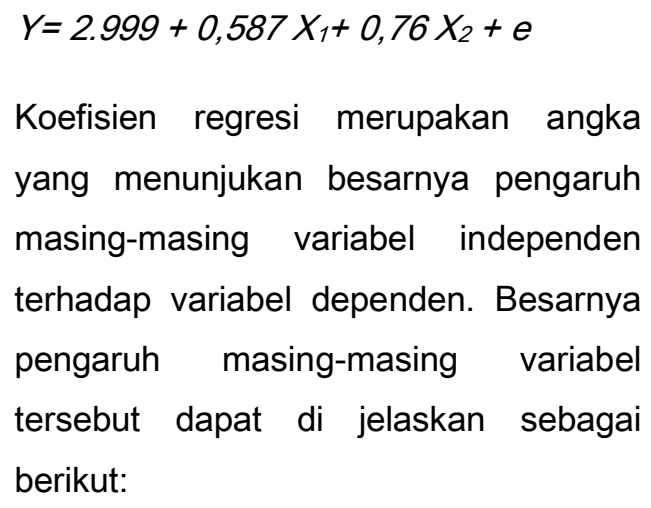
yang menunjukan besarnya pengaruh masing-masing variabel independen terhadap variabel dependen. Besarnya pengaruh masing-masing variabel tersebut dapat di jelaskan sebagai berikut:

1) Nilai konstanta 2,999 menunjukkan bahwa ketika semua variabel bebas (country of origin dan perceived quality) dianggap konstan atau tidak mengalami perubahan maka minat beli sebesar 2,999

2) Country of origin (X1) terhadap minat beli $(\mathrm{Y})$

Nilai koefisien untuk variabel country of originsebesar 0,587 hal ini menyatakan bahwa jika kenaikan country of originsebesar 0,587 maka variabel minat beli $(Y)$ akan mengalami peningkatan sebesar 0,587 dengan asumsi variabel lain tetap atau tidak mengalami perubahan.

3) Perceived quality (X2) terhadap minat beli $(\mathrm{Y})$ Nilai koefisien untuk variabelperceived quality untuk sebesar 0,076 hal ini menyatakan bahwa jika kenaikan perceived qualitysebesar 0,076 maka variabel minat beli $(Y)$ akan mengalami peningkatan sebesar 0,076 dengan asumsi variabel lain tetap atau tidak mengalami perubahan.

\subsubsection{Uji Hipotesis}

1) Uji t ( Parsial )

Pengujian ini dilakukan untuk mengetahui pengaruh masingmasing variabel independen terhadap variabel dependen. Caranya adalah dengan membandingkan nilai statistik $t_{\text {hitung }}$ dengan nilai statistik tabel pada nilai signifikan (a) sebesar $5 \%$. Masing-masing variabel independen dikatakan mempunyai nilai yang signifikan apabila nilai thitung $>$ tabelatau apabila probabilitas $<5 \%$. Jika nilai thitung $>$ $t_{\text {tabel }}$ atau nilai signifikan $<0,05$ maka terdapat pengaruh signifikan dari variabel independen terhadap variabel dependen. Dan sebaliknya jika nilai $t_{\text {hitung }}<t_{\text {tabel }}$ atau nilai signifikan >0,05 maka tidak terdapat pengaruh signifikan dari variabel independen terhadap dependen . Adapun cara mencari $t_{\text {tabel }}$ ditentukan berdasarkan Tabel 
Distribusi Nilai $\mathrm{t}$ dengan tingkat signifikan $5 \%$ dengan jumlah variabel $x(k=2)$. Dengan rumus taraf signifikan $t_{\text {tabel }}=\mathrm{t}(\alpha / 2$ : $\mathrm{n}-\mathrm{k}-1)$ :

$$
\begin{aligned}
\mathrm{n}= & 70 \\
\mathrm{t} & =(\mathrm{a} / 2: \mathrm{n}-\mathrm{k}-1) \\
\mathrm{t} & =(0,05: 70-2-1) \\
\mathrm{t} & =(0,025: 67) \\
\mathrm{T} & =1,996(\mathrm{n}=67)
\end{aligned}
$$

Jadi nilai $T_{\text {tabel }}$ sebesar 1,996

Tabel 3.7. Hasil uji t

\begin{tabular}{|l|l|l|l|l|}
\hline Variabel & Koefis & $\mathrm{T}_{\text {hitung }}$ & Sig. & Kesimpulan \\
\hline ien & & 1.286 & .203 & \\
\hline $\begin{array}{l}\text { Country of } \\
\text { origin }\end{array}$ & .587 & 3.140 & .003 & $\begin{array}{l}\text { Berpengaruh } \\
\text { positif dan } \\
\text { dan signifikan }\end{array}$ \\
\hline $\begin{array}{l}\text { Perceived } \\
\text { quality }\end{array}$ & .076 & .566 & .573 & $\begin{array}{l}\text { Berpengaruh } \\
\text { positif dan } \\
\text { tidak dan } \\
\text { signifikan }\end{array}$ \\
\hline
\end{tabular}

a) Dependent Variabel: minat beli Sumber: Data primer yang diolah, 2019 Hasil perhitungan uji $t$ dengan menggunakan program SPSS 16 for windows dapat di lihat pada tabel 4.6. diatas. Berdasarkan tabel tersebut dapat diketahui bahwa besarnya pengaruh masing-masing variabel independen terhadap variabel dependen sebagai berikut:

1) Untuk variabel country of oigin $\left(X_{1}\right)$ didapat $\mathrm{T}_{\text {hitung }}$ sebesar 3.140 dan signifikansi 0,003. Menunjukkan thitung $(3,140)>t_{\text {tabel }}(1,996)$ sehingga dapat disimpulkan bahwa variabel country of origin $\left(\mathrm{X}_{2}\right)$ berpengaruh positif dan signifikan terhadap minat beli.

2) Untuk variabel perceived quality $\left(X_{2}\right)$ didapat $T_{\text {hitung }}$ sebesar 0,566 dan signifikansi sebesar 0,573. Menunjukkan $\mathrm{T}_{\text {hitung }}\left(0,566<\mathrm{t}_{\text {tabel }}\right.$ $(1,996)$ sehingga dapat disimpulkan bahwa perceived quality positif dan tidak signifikan terhadap minat beli.

\section{KESIMPULAN}

Berdasarkan hasil analisis dan pembahasan tentang pengaruh country of origin dan perceived quality terhadap minat beli sepeda motor Honda Beat di Kota Sumbawa. Maka dapat ditarik beberapa kesimpulannya yaitu:

1) Terdapat pengaruh positif dan signifikan antara variabelCountry of origin terhadap minat beli sepeda motor Honda Beat di Kota Sumbawa.

Hal ini berarti semakin tinggi pengaruh country of origin maka semakin tinggi minat beli sepeda motor Honda Beat di Kota Sumbawa. Nilai koefisien $X_{1}$ sebesar 0,587 dan dengan nilai signifikansi sebesar 0,03lebih kecil dari 0,05, maka dapat dinyatakan bahwa country of origin berpengaruh positif dan signifikan terhadap minat beli sepeda motor Honda Beat di Kota Sumbawa.

1) Terdapat pengaruh positif namun tidak signifikan antara variable perceived 
quality terhadap minat beli sepeda motor Honda Beat di Kota Sumbawa.

Hal ini mengatakan bahwaperceived qualitytidak mempengaruhi minat beli sepeda motor Honda Beat di Kota Sumbawa secara signifikan. Hal ini terjadi karena nilai koefisien $\mathrm{X}_{2}$ sebesar 0,076 dan dengan nilai signifikansi sebesar 0,573 lebih besar dari 0,05, maka dapat dinyatakan bahwa perceived quality berpengaruh positif dan tidak signifikan terhadap minat beli sepeda motor Honda Beat di Kota Sumbawa.

2) Terdapat pengaruh positif dan signifikan secara bersama-sama antara variabel Country of origin dan Perceived quality terhadap minat beli sepeda motor Honda Beat di Kota Sumbawa.

Hasil ini dilihat dari nilai $F_{\text {hitung }}$ lebih besar dari $F_{\text {tabel }}$ sebesar6,482 $>3,13$ dengan nilai signifikansi $0,002<0,05$ artinya country of origin dan perceived quality secara bersama-sama berpengaruh terhadap minat beli sepeda motor Honda Beat di Kota Sumbawa.

\section{DAFTAR PUSTAKA}

1. Alma. (2014). manajemen pemasarandan pemasaran jasa. Bandung: Alfabeta.

2. Atika, C. (2018). Pengaruh Negara Asal, Citra Merek, dan Persepsi Kualitas terhadap Minatbeli smartphoneOppo di kotabandar lampung. Universitas Lampung.

3. Bek, M. (2016). Pengaruh Kesadaran Merek, Asosiasi Merek,Presepsi Kualitas dan Loyalitas Merek Terhadap Keputusan Pembelian Roko Merek Sampoerna(studi pada mahasiswaUniversitas

Brawijaya). Jurnal IImiah FEB, 4(1).

4. Cateora, R. P., \& Graham, L. J. (2011).Pemasaran Internasional (13 ed.). (S. T. Pasaribu, Trans.) Jakarta: Salemba Empat.

5. Ghozali, I. (2011). Aplikasi Analisis Multivariable dengan Program IBM . Semarang : Badan Penerbit Universitas Diponegoro.

6. Harjuno, P. (2018). Pengaruh Kualitas Produk, Presepsi Harga, dan Citra Merek Terhadap Keputusan Pembelian Motor Matic Honda Scoopy (studi kasus pada mahasiswa Universitas Negery Yogyakarta). Universitas Negeri Yogyakarta. 
7. Keegan, W. J., \& Mark, C. G. (2013). Global Marketing. Harlow: Pearson.

8. Keller, K. L. (2013). Strategic Brand Management. 4th Edition. US: Pearson.

9. Kotler, P. (2011). Manajemen Pemasaran. Jakarta: PT. Indeks.

10. Kotler, P., \& Amstrong, G. (2012). Prinsip-prinsip Pemasaran. Edisi 13. Jakarta: Erlangga.

11. Kotler, P., \& Kevin , L. K. (2016). Marketing Management. 15th Edition. Inc: Pearson Education.

12. Lupiyadi, R. (2013). Manajemen pemasaran jasa. Jakarta : Salemba Empat.

13. Maksaoka, I. M., \& Rahyuda, W. I. (2016). Peran Brand Image dalam Memediasi Country of origin terhadap Purchase Intention. E-Jurnal Management Unud, 5(4), 1690-1716.

14. Putra, I. B., \& Ni, W. Suprapti. (2019). Pengaruh Presepsi Negara Asal (country of origin) terhadap Niat Beli yang di mediasi Citra Merek. E-Jurnal Manajemen, 8(8), 5240-5266.

15. Putri, T. W., Suharyono, \& Edi, Y. (2015). pengaruh Country Of Origin dan Global Brand Image terhadap minat beli dan keputusan pembelian ( survei pada konsumen yang memebeli smartphone samsung Galaxy di Asia tenggara.

16. Saladin, D. (2012). Manajemen Pemasaran,Analisis

Perencanaan, Pelaksanaan Unsur-unsur Pemasaran. Bandung: CV. Linda Karya.

17. Sanusi, A. (2012). Metode penelitian bisnis. Jakarta: Salemba Empat.

18. Septianda, S. (2017). Pengaruh Country Of Origin dan Persepsi Kualitas terhadap Minat Beli( survei pada mahasiswa fakultas ilmu sosial dan ilmu politik pengguna smartphone Xiaomi). Universitas Sumatera Utara.

19. Sugiyono. (2014). Metode penelitian bisnis pendekatan kuantitatif, 